\title{
The role of trust in shaping mother-and-child relationship: Indigenous psychological analysis
}

Tyas, Tri Hayuning

Center for Indigenous and Cultural Psychology, Faculty of Psychology, Universitas Gadjah Mada, Yogyakarta, Indonesia (t.h.tyas@ugm.ac.id)

Yuniarti, Kwartarini Wahyu $\bowtie$

Center for Indigenous and Cultural Psychology, Faculty of Psychology, Universitas Gadjah Mada, Yogyakarta, Indonesia (kwartarini_yuniarti@yahoo.com)

Kim, Uichol

College of Business Administration, Inha University, Incheon, Korea (uicholk@yahoo.com)

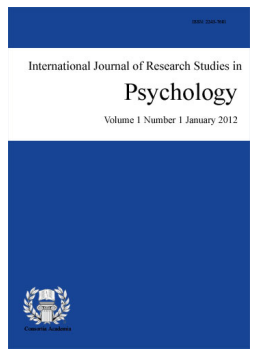

ISSN: 2243-7681 Online ISSN: 2243-769X

OPEN ACCESS

\section{Abstract}

The purpose of this study was to examine the role trust plays in shaping the parent-child relation and the reasons why children trust and distrust their mother. A total number of 507 university students (males $=140$, females $=367$ ) at the Universitas Gadjah Mada completed an open-ended questionnaire that asked how much they trust their mothers and the reason why they trust and distrust their mothers. The data was analyzed using indigenous psychological approach of analyzing the content of open-ended responses, categorization of the responses, and cross tabulating. Result from these study shows that $57.63 \%$ of participants' trust their mothers to a great extent and $33.69 \%$ of respondents largely trust their mothers. Second, there are five main categories of reasons for trusting mothers and six main categories of reasons for distrusting their mothers that have emerged. First category focuses on mother's personal quality such as honesty and reliability. Second, what mothers are able to bring into the life being that involved mother critical role for children surviving the world, physically, psychologically, and socially. Third, what exist between the relations counts the trust existence. Fourth, the perceived figure of mother. Fifth, the role of self in deciding when to trust. The six categories for distrust suggest the unconditional trust toward mother that indicate the strong bend of trust-relation between mother and children once it is established. It reaches to the conclusion that reasons for trusting mother is much colored by the spiritual and emotional nuance, whereas honesty and reliability, empathy, give the best, closeness and consanguinity, are factors that play quite important role in the development or establishment of trust to mother. From the reasons of trust and distrust, we learned that trust can play as the modality to consider act or to relate and as a product or result and is dynamic rather than static.

Keywords: Trust; distrust; mother-child relationship; indigenous psychology; Indonesia 


\section{The role of trust in shaping mother-and-child relationship: Indigenous psychological analysis}

\section{Introduction}

This study is about the reason for the students trust to their mothers and how it shapes the parents-child relation. There are some reasons why research about children's trust towards mother is necessary. Firstly, mother is the first person for one to connect with. Relation with mother happens since the very beginning of one's life and it continues lifetime. It means that the first social relation established is between children and mother. Secondly, mother-and-child relation that seems universal may have different facets that reflect on how culture and social change influence children's trust towards mother and its consequences. Thirdly, this study also attempts to investigate the dynamic of trust and distrust or mistrust towards mother. Identifying factors that enable the development and maintenance of trust of the children towards their mothers may give important insights of what constitute trust in general and its re-establishment once it is lost in a specific cultural context.

\section{Literature review}

\subsection{Trust and human interactions}

Many scholars have emphasized the centrality of trust in human interactions (Williams, 2001; Lewicki et al. 1998; Lewicki et al., 2006; Miller 2004). Although there is no single universally accepted perspective on trust, there are some elements that can be qualified as commonalities across all the approaches. These common elements not only cement an implicit "common" understanding of the concept of trust but also emphasize the fundamentality of trust in creating and maintaining human interactions. Among them are "prediction" (Maguire et al., 2001; Möllering, 2001), "willingness" (Hardin 2001; Maguire et al., 2001; Lewiciki et al., 1998; Williams, 2001; Mayer et al., 1995), "expectation" (Möllering, 2001; Williams, 2001; Lewiciki et al., 1998; Hall, 2002; Doney, Cannon, \& Mullen, 1998; Rousseau et al., 1998) "vulnerability" (Doney, Cannon, \& Mullen, 1998, Mark A. Hall et al., 2001; Rousseau et al., 1998), and "faith" (Möllering, 2001; Lewis \& Weigert, 1985). All in all, scholars from across many disciplines agree that trust is the key element to human relationship; as Lewis and Weigert succinctly put it "trust in general is indispensable in social relationships" (Lewis \& Weigert, 1985).

Trust is not static as some scholars have treated it (Rousseau et al., 1998), but rather than that, it is dynamic and an indication of the viability of relationship. Solomon and Flores (1998) argue that trust is not something that simply exists from the beginning, it is an emotional skill, an active and dynamic part of our lives that we build and sustain with our promises and commitments, our emotion and integrity. Yamagishi (1998) explained that there are two types of trust need to be distinguished, generalized trust and assurance. Generalized trust is a general belief in human benevolence. In other words, human naturally possesses trust and therefore people in general can be trusted. Assurance trust refers to the trust subjected to particular person who is perceived to be harmless. Trust is important factor that indicates the quality of parent-child relationship (Murray, 2009). There are some factors influence parent-child relationship, among those is child-rearing pattern. Mother and father have different kind of relationship with their children (Kim, 1995).

\subsection{The wording trust and no-trust (percaya atau tidak percaya): Two dichotomous words in meaning}

The word trust is "equal" to percaya in Bahasa Indonesia. Although it is generally accepted as 'equal'; percaya was not really been studied in the social context. Many of the studies focus on organizational or consumer behavior rather than the use of language in the everyday life. Unlike in English terms that distinguish between loss of trust (mistrust) and never having trust (distrust), there is no word in Bahasa Indonesia that 
The role of trust in shaping mother-and-child relationship: Indigenous psychological analysis

distinguish the different between mistrust and distrust. Generally speaking, percaya and tidak percaya is a as two dichotomous terminology.

Research from East Asia stated that relationship between a person and other people constitute the basic foundation in constructing social structure (Choi \& Kim, 2006; Yang, 2006). As it was presented by Hwang (2006) and Yang (2006) that in Chinese culture, the concept of guanxi (relationship) is deemed central to explain social interactions in the contexts of families, schools, work places and communities. In Japan, amae becomes the key component in establishing interpersonal relations (Yamaguchi \& Ariizumi, 2006). Whilst in Korea, attachment and affection (concept of Jung) becomes an element of bonding for the family, friends, and colleagues (Choi et al., 2006). According to Hakim (2012), researchers in East Asia are in agreement to the notion that Confucian values remain as a strong influence of social characteristics in East Asia (Megawangi, et al., 1995). Rozman (1991) stated that Confucianism values are evidence in families and traditions by placing family harmony as the foundation in establishing community harmony. Up until the present, Confucianism interaction patterns apparent in Japanese and Korean communities include orientation to group, acceptance of authority, mutual dependence, avoidance of conflict, awareness to seniority, and compliance.

In the present study, we examined the reason for the students (the study participants) trust the mothers and how it shapes the mother-and-child relationship based on the teenage children's perspective. This study frames all syntax in the context of "parents-child" relationship, so the wording of students and children are referring to the same group. The research aimed to get a better understanding of the reason for children to trust or distrust their mothers in Indonesia context. Understanding what factors which contribute to the development of trust and distrust towards mothers in Indonesia context, will offer valuable information for parents to maintain their parent-child relation by taking attention towards the aspect that contribute to trustful-relationship.

\section{Methods}

\subsection{Study participants}

A number of 507 university students participated in this research. There were 140 males and 367 females within age range 16 to 25 years old. Based on the data, they were all Indonesians coming from 36 ethnic backgrounds and have been living in Yogyakarta, where this study took place, for a more than 2 years. Yogyakarta is a moderate city in size and the Indonesian most popular destination for studying especially the high school and the university levels. Indonesia is a multicultural society where the acculturation process is happening in people everyday life. The ethnical or religious background of Indonesians is moving onto dynamic process, which requires ways to see Indonesians as collective identity rather than fragmented ethnical or religious identity. Yogyakarta, where the research took place, is a perfect example of multicultural society.

\subsection{Measurements}

The instrument used in the survey of this study was an open-ended questionnaire, which was developed by Kim (2009) focusing on Trust. Data were collected as part of a bigger study conducted by the Center of Indigenous and Cultural Psychology (CICP), in Yogyakarta, Indonesia. This article reports only the reason for the students trust and distrusts their mother by using an open-ended questionnaire pertaining to the trust towards individuals and institutions. The first part of questionnaire was concerned with individual general evaluation how much they trust their mothers by 5 items using five-point scale that range from 5 'very much' or sangat percaya to 1 'not at all' or tidak percaya. The second part of questionnaire was asking for what reason they trust and distrust their mothers. There is no limitation for the subject answering the questions. The data was analyzed using indigenous psychological approach of analyzing the content of open-ended responses, categorization of the responses and cross tabulating with background/ demographic information. Descriptive statistics were used to give a general picture of the data. 


\section{Results}

\subsection{Descriptive statistic}

Result from this study shows that $57.63 \%$ of participants' trust their mothers "to a great extent/ very much" and $33.9 \%$ of respondents "largely trust/ much" their mothers. Meanwhile 5.9\% respondent reported "somewhat trust" to their mothers and $2.2 \%$ "little trust" and $0.4 \%$ "didn't trust at all". The proportion of female and male participants in responding the question is slightly different, as explained in table 1.

\section{Table 1}

Total response and percentage of participants

\begin{tabular}{lcccccc}
\hline \multirow{2}{*}{ Responses } & \multicolumn{7}{c}{ Number and percentage of participants } \\
\cline { 2 - 7 } & $\mathrm{N}$ & Female & $\mathrm{N}$ & Male & $\mathrm{N}$ & Total \\
\hline Very much & 202 & 55.0 & 90 & 64.3 & 292 & 57.63 \\
Much & 134 & 36.5 & 38 & 27.1 & 172 & 33.69 \\
Somewhat & 22 & 6.0 & 8 & 5.7 & 30 & 5.9 \\
Little & 7 & 1.9 & 4 & 2.9 & 11 & 2.2 \\
Not at all & 2 & 0.5 & 0 & 0 & 2 & 0.4 \\
\hline
\end{tabular}

\subsection{Categorization of the responses}

All responses of open-ended questionnaires were compiled into a database to secure its originality. The analyses used the first significant responses of the subject towards the questions of both trust and distrust. The smallest categorization (specific themes) then was ranked based on its frequency. There were 46 specific themes for the reasons to trust mother and 52 for the reasons for not to trust mother. In this study, the specific themes were re-grouped in which it organized some attitude and behavior possessed by or attached to the subject matter. The specific themes for trust were re-grouped into seven groups and six groups for the distrust. The grouping contributes significantly to identify main themes that contribute to the trust or distrust towards mother. Within these groups, those specific themes then reorganized into several themes based on specific criteria. Figure 1 explains about the process of re-grouping.
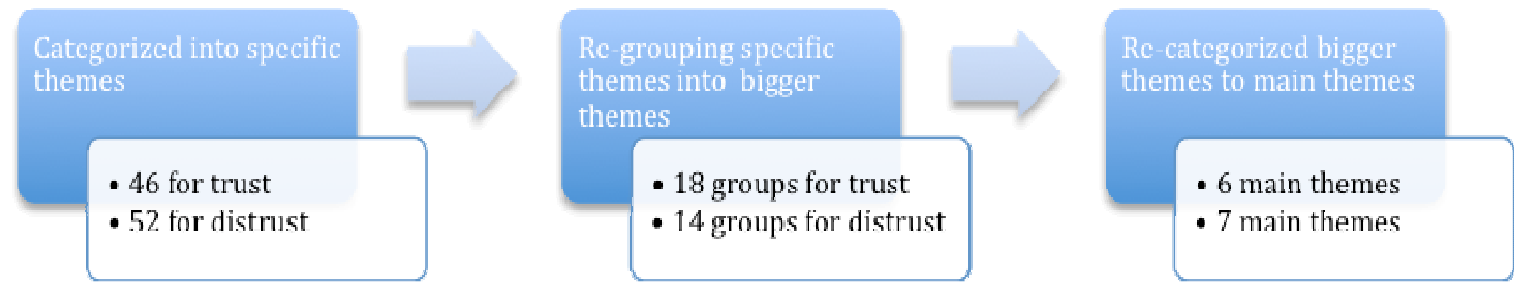

Figure 1. Process of regrouping trust/distrust responses

Table 2 shows the ten most frequent answers that were categorized in the specific themes of the response for trusting-and-distrusting-mother questions. While, the following table 3 and table 4 provide information about the complete categorization for trust and distrust responses based on the process of categorization and the gender differences. 
The role of trust in shaping mother-and-child relationship: Indigenous psychological analysis

Table 2

The ten most frequent specific responses for trusting and distrusting mother

\begin{tabular}{lllllrr}
\hline & \multicolumn{3}{c}{ Trust Response } & \multicolumn{2}{c}{ Distrust Response } \\
\cline { 2 - 7 } Rank & $\begin{array}{l}\text { Specific } \\
\text { categorization }\end{array}$ & $\mathrm{N}$ & $(\%)$ total & Specific categorization & N & \\
\hline 1 & Consanguinity & 44 & 8.65 & No reason to distrust & 66 & 12.97 \\
2 & Feeling close & 41 & 8.05 & Dishonest & 38 & 7.47 \\
3 & Honest & 39 & 7.66 & Not keeping the secret & 36 & 7.07 \\
4 & Give the best & 36 & 7.07 & Having different point of view & 34 & 6.68 \\
5 & Won't lead astray & 30 & 5.89 & Unconditional trust & 33 & 6.48 \\
6 & Understand me & 29 & 5.70 & White lies & 29 & 5.70 \\
7 & Proven & 27 & 5.31 & Hiding something & 26 & 5.11 \\
8 & Love me & 27 & 5.31 & Conservative/obsolete information & 16 & 3.14 \\
9 & My mother & 26 & 5.11 & Lack of knowledge & 13 & 2.55 \\
10 & Nurturing & 22 & 4.32 & Inconsistent & 11 & 2.16 \\
\hline
\end{tabular}

Table 3

Complete result of trust categorization and gender

\begin{tabular}{|c|c|c|c|}
\hline \multirow{2}{*}{ No } & \multirow{2}{*}{ Category: Main themes and group of specific themes } & \multicolumn{2}{|c|}{ Total } \\
\hline & & $\mathrm{N}$ & $\%$ \\
\hline \multirow[t]{6}{*}{1.} & Mother's personal quality & & \\
\hline & 1.1. Honesty and reliability & 65 & 12.8 \\
\hline & 1.2. Kindness and maturity & 36 & 7.07 \\
\hline & 1.3. Knowledgeable & 21 & 4.13 \\
\hline & 1.4. Spirituality & 6 & 1.12 \\
\hline & Total & 128 & 25.15 \\
\hline \multirow[t]{8}{*}{2.} & What mother brings into life being & & \\
\hline & 2.1. Consanguinity & 44 & 8.65 \\
\hline & 2.2 Empathy & 59 & 11.59 \\
\hline & 2.3. Give the best & 53 & 10.41 \\
\hline & 2.4. Psychological and intellectual support & 30 & 5.90 \\
\hline & 2.5. Taking care & 29 & 5.70 \\
\hline & 2.6. Material support & 3 & 0.60 \\
\hline & Total & 218 & 42.83 \\
\hline \multirow[t]{5}{*}{3.} & What exist between the relation or the process of interaction & & \\
\hline & 3.1. Closeness and transparency & 59 & 11.60 \\
\hline & 3.2. Reciprocal & 9 & 1.77 \\
\hline & 3.3. Good communication & 2 & 0.40 \\
\hline & Total & 70 & 13.75 \\
\hline \multirow[t]{5}{*}{4.} & Perceived good figure of mother & & \\
\hline & 4.1. Won't lead astray & 30 & 5.90 \\
\hline & My mother & 26 & 5.70 \\
\hline & 4.3 Role model & 13 & 2.56 \\
\hline & Total & 75 & 14.16 \\
\hline \multirow[t]{4}{*}{5.} & Self-determined & & \\
\hline & 5.1. Love her & 13 & 2.56 \\
\hline & 5.2. Situational & 8 & 1.57 \\
\hline & Total & 21 & 4.13 \\
\hline
\end{tabular}

Table 3 shows that among the five main themes, what mother brings into life being themes is the most frequent answer. It is then followed by mother personal quality, perceived good figure of mother, what exist between the relation and self-determined themes. Among those within the category mother brings into being, consanguinity is the most frequent answer followed by empathy, give the best, psychological and intellectual support, taking care and material support. Consanguinity suggests that mother gave birth to them and that their mothers will not betray her natural role. The different response between males and females is quite slight. 
Tyas, T. H., Yuniarti, K. W., \& Kim, U.

\section{Table 4}

Complete result of distrust categorization

\begin{tabular}{|c|c|c|c|}
\hline \multirow{2}{*}{ No } & \multirow{2}{*}{ Category } & \multicolumn{2}{|c|}{ Total } \\
\hline & & $\mathrm{N}$ & $\%$ \\
\hline \multirow[t]{5}{*}{1.} & Mother's personal quality & & \\
\hline & 1.1. Dishonesty and unreliability & 149 & 29.08 \\
\hline & 1.2. Knowledge ability & 52 & 10.22 \\
\hline & 1.3. Personal character & 50 & 9.82 \\
\hline & Total & 251 & 49.12 \\
\hline \multirow[t]{4}{*}{2.} & What mother fails to give & & \\
\hline & 2.1. Empathy & 16 & 9.04 \\
\hline & 2.2. Psychological and intellectual support & 13 & 2.55 \\
\hline & Total & 29 & 11.59 \\
\hline \multirow[t]{5}{*}{3.} & What exist between the relation or the process of interaction & & \\
\hline & 3.1. Different point of view & 34 & 6.68 \\
\hline & 3.2. Control & 18 & 3.54 \\
\hline & 3.3. Distance & 2 & 0.39 \\
\hline & Total & 54 & 10.51 \\
\hline \multirow[t]{3}{*}{4.} & Perceived figure of mother & & \\
\hline & 4.1. Breaking norms, not a good mother, step mother & 7 & 1.38 \\
\hline & Total & 7 & 1.38 \\
\hline \multirow[t]{4}{*}{5.} & Self-determined & & \\
\hline & 5.1. Situational & 17 & 3.34 \\
\hline & 5.2. I trust myself & 11 & 2.16 \\
\hline & Total & 28 & 5.50 \\
\hline \multirow[t]{5}{*}{6} & Unconditional trust & & \\
\hline & 6.1. No reason to distrust & 66 & 13.00 \\
\hline & 6.2. Human imperfection & 33 & 6.50 \\
\hline & 6.3. Always trust & 20 & 14.00 \\
\hline & Total & 119 & 23.38 \\
\hline
\end{tabular}

Table 4 shows that among the six main themes exclude others, mother's personal quality is the most frequent answer followed by unconditional trust, what exist between the relation, what mother fails to give, self-determined, and perceived figure of mother. Among those within the category mother's personal quality, dishonesty is the most frequent specific themes of the response. The response difference between males and females is quite slight.

\section{Discussion}

This article examined how the students trust their mothers. It attempts to describe the level of trust towards mother, the reason for trusting and distrusting mother and how it shapes the relation between mothers and children. We argued that children trust towards mother in Indonesian context have a specific route of reasoning. Kim (1995) argued the relational mode of mother-child relationship in Korea and Japan, which emphasizes the central issues of mother-child relationship in its specific context. The result of the study shows that $91.32 \%$ of the respondents trust their mothers to a large extent. The difference between males and females was only slightly. It suggests that generally speaking children trust their mothers to a large extent.

The five main themes for trust and six main themes for distrust towards mother give information about the main aspects of the trust development and maintenance of trust, in this regards, towards mother. The grouping of specific themes helps to understand the commonalities between the broad specific themes. However, it is necessary also to examine carefully the broad specific themes and read through the narrative of open-ended questions to understand the connection between the reasons given.

What mother brings into life being theme explain children's perception about what has been given by mother to them which has contributed and influence so much to their present life. Mother's understanding about their 
The role of trust in shaping mother-and-child relationship: Indigenous psychological analysis

situation, giving the best, and the fact that mother had delivered them in to the world (consanguinity), are the three most frequent answers followed by psychological support, taking care and material support. The emotional nuance is quite thick in the narrative explanation. These findings suggest the feeling emerged from what has been provided by mother who covers almost all aspects of human need for surviving physically, psychologically, and socially all together, is critical for the trust development and maintenance.

Mother personal quality themes explain children perception of what kind of quality that counts for the growing of trust towards mother. Honesty and reliability are ranked highest followed by kindness and maturity, knowledgeable and spirituality. This finding suggests honesty and reliability, kindness and maturity and knowledgeable, along with spirituality, all together supports and plays quite important role in the growing and the maintenance of trust between children and mother. The quality or character of the trustee, in this regard is mother, is important.

Perceived good figure of mother theme explain about how a child sees the mother as a figure. The findings suggest that children believe that mothers will not let them into doing things wrong and be a good person as mother models it. Trust here resulted from the preexistence belief about what mother should be and involved children expectation to some extent.

What exist in the relation explain about aspect that result in the existence of trust. On the other words, what is inside the relation determine the existence of trust. Closeness and transparency, reciprocal and good communication plays important role in this regard. This finding suggests that those aspects should be considered to exist for the growing of trust between mother and children.

Last but not least, self determined theme, attempt to explain how individual decided why and when to trust mother by looking into her/himself and evaluate the situation. The feeling of love mother and on specific situation only is two important themes. These findings suggest that children may decide whether or not to trust mother by evaluating their own feeling or based on the situation. Slightly different from the reason for trusting mother, the distrust response mainly subjected to mother's personal quality followed by what exist between the relation what mother fails to give, self determined, and perceived figure of mother. Interestingly, unconditional trust has emerged as a significant response for the question "For what reason do you distrust your mother?" Before we discuss about the unconditional trust response, we will explain about the five similar responses with trust question.

In mother's personal quality theme, dishonesty and unreliability dominate the answers. It is followed by lack of knowledge and experience and personal (not good) character of mother. This finding suggests that mother's dishonesty play important role in the erosion of trust. What exist between the relation themes, whereas having different point of view, control issue, and distance play important role in the development of trust? Those aspects count for predicting the quality of relation between individuals and therefore important for the development and the maintenance of trust. What mother fails to give theme does not harvest response as in the trust question. The existence of mother's empathy and psychological support are emerged. This finding suggests that empathy and psychological support are most important factors in comparison with any other kind of support as it was mentioned in the trust question. In order to see the complete figure of reasons for trusting and the fact that the failure for mother giving those support, did not really influence of the erosion of trust towards mother.

Self-determined theme is similar to the trust question. The evaluation of self and the situation are both play important role to the erosion of trust. Meanwhile perceived figure of mother, which captures the bad figure of mother, reflects the experience of bad attitude of mother influence the erosion of trust towards mother to some extent.

The unconditional trust theme attempts to explain how respondents' trust-response for the question of distrust towards mother. The response "no reason to distrust mother" is quite frequently emerged. And if so, many add that mother is imperfect humankind. Some other explicitly giving the response that they always trust 
Tyas, T. H., Yuniarti, K. W., \& Kim, U.

mother

From the variety of responses for questions trust and distrust, we learned that although we examined the trust towards mother, we found there are some complexities how trust can grow on one hand, and how it erodes on the other hand. It is explicit from the findings that the reason to trust mother has been going through a process of reasoning. However, it has different route to compare with the factors that erode trust. This study also shows that for the trust is not static, but rather than that it is dynamic and indicates of the viability of relationships, as Rousseau et al. (1998) argued "trust changes over time- developing, building, declining, and even resurfacing in long-standing relationships."

\section{Conclusions}

The constellation of reasons for trusting mother is much colored by the spiritual and emotional nuance, which is derived from what mother's brings onto being group. Whereas honesty and reliability, empathy, give the best, closeness and consanguinity, are factors that play quite important role in the development or establishment of trust to mother. Meanwhile, mother's personal quality is the most important factor to create distrustfulness among the children towards mother. Unconditional trust exists between the trust and distrust questions to add the dynamic of mother-child relation. From the reasons of trust and distrust, we learned that trust can play as the modality to consider act or to relate and as a product or result and its dynamic rather than static. The unconditional trust toward mother may indicate that trust to mother has a specific character. Looking in closely to the answer of question why subject distrust their children; the immediate response of trustfulness shows that once trust established (it needs powerful force to break it).

Students saw trust as a result of the process, which already happened or has been happening at the moment. They much consider consequences of putting trust on their mother so that they can predict specific matter in the future, when, for what matter and how they can trust their mother. Trust grows. It is partly as a result of relational process between mother and children and they study continuously about it. Both parties are active agents in creating trust, not as a mechanical or mathematical logic.

\subsection{Limitation of the study}

The result of very much to not at all, did not correspond to the reason they given why they trust their mothers. For example, the reason for very much respond: because she's my mother; as much as their reasons for somewhat respond. The explanation could be the nature of percaya, in this regard percaya towards mother. What it mean by sangat percaya, percaya, kurang percaya, sedikit percaya, and sama sekali tidak percaya cannot be revealed by this questionnaire. We suggest future studies to focus on how people use and give meaning the word percaya.

\subsection{Recommendation}

As it was learnt from the data, very limited trust built through instrumental stuffs (eg., money, facilities, etc), rather than that most were formed and fillid up by and with emotion and spiritual. With regard to that, it is very important to parents realising that giving only materials for their children without being tailored in a warm and strong emotional/affectionally bound and spiritual package may not lead into the development of a stron basic trust for their children. This issues is very crucial since in the late decade, parents are gone to works and most probably forget spending time for showing their affection bound to their children. It is also recommended for the following research to put on the more representative sampling, and so generalisation can be better made.

Note: The article was presented in the 8th Biennial Conference of Asian Association of Social Psychology at New Delhi, India on December 2009. 


\section{References:}

Choi, S. C. \& Kim, K., (2006). Naive psychology of Koreans' interpersonal mind and behavior in close relationships. In U. Kim, K. S. Yang, \& K. K. Hwang (Eds.), Indigenous and cultural psychology: Understanding people in context (pp. 357-369). New York: Springer.

Doney, P. M., Cannon J. P., \& Mullen M. (1999). Understanding the influence of national culture on the development of trust. The Academy of Management Review. 23, 601-620.

Flores, F., \& Solomon, R. C. (1998). Creating trust. Business Ethics Quarterly, 8(2), 205-232.

$<\underline{\text { http://dx.doi.org/10.2307/3857326 }>~}$

Hakim, M. A., Thontowi, H. B., Yuniarti, K. W., \& Kim, U. (2012). The basis of children's trust towards their parents in Java, ngemong: Indigenous psychological analysis. International Journal of Research Studies in Psychology, 1(2), 3-16. <http://dx.doi.org/10.5861/ijrsp.2012.v1i2.78>

Hall, A. M. (2002). Law, medicine, and trust. Sanford Law Review, 55, 463-527. $<\underline{\text { http://dx.doi.org/10.2307/1229596> }}$

Hall, M. A., Dugan, D., Zheng, B., \& Mishra, A. K. (2001). Trust in physicians and medical institutions: What is it, can it be measured, and does it matter? The Milbank Quarterly, 79, 613-639. $<$ http://dx.doi.org/10.1111/1468-0009.00223>

Hardin, R. (2001). Conceptions and explanations of trust. In Cook, K., (Ed.) Trust in society (pp. 3-39). New York: Russel Sage Foundation.

Hwang, K. K. (2006). Constructive realism and Confucian relationalism: An epistemological strategy for the development of indigenous psychology. In U. Kim, K. S. Yang, \& K. K. Hwang (Eds.), Indigenous and cultural psychology: Understanding people in context (pp. 49-72). New York: Springer.

Igarashi,T., Kashima, Y., Kashima, E., Farsides, T., Kim, U., Strack, F., Werth, L., \& Yuki, M. (2008). Culture, trust and social networks. Asian Journal of Social Psychology 11, 88-10. <http://dx.doi.org/10.1111/j.1467-839X.2007.00246.x>

Kim, U. (1995). Individualism and collectivism. A psychological, cultural and ecological analysis. NIAS Report Series 21. NIAS Publication.

Kim, U. (2009). Indigenous psychological analysis of Trust/happiness/self/achievement/parent-child relationshp/coping with disaster. Unpublished manuscript, Inha University, Incheon, Korea.

Lewis, J. D., \& Weigert, A.(1985). Trust as a social reality. Social Forces, 63, 967-985.

Lewicki, R. J., Tomlinson, E. C., \& Gillespie, N. (2006). Models of interpersonal trust development: Theoretical approaches, empirical evidence, and future directions. Journal of Management, 32, 991-1022. <http://dx.doi.org/10.1177/0149206306294405>

Lewicki, R. J., Mcallister. D., \& Bies, R. (1998).Trust and distrust: New relationships and realities. Academy of Management Review, 23, 439-458.

Miller, K. E. (2004). Beyond the frontstage: Trust, access, and the relational context in research with refugee communities. American Journal of Community Psychology, 33, 217-227. <http://dx.doi.org/10.1023/B:AJCP.0000027007.14063.ad>

Maguire, S., Phillips, N., \& Hardy, C. (2001). When 'silence= death', keep talking: trust, control and the discursive construction of identity in the Canadian HIV/AIDS treatment domain. Organization studies, 22(2), 285-310. <http://dx.doi.org/10.1177/0170840601222005>

Mayer, R. C., Davies, J. H., \& Schoorman, F. D. (1995). An integrative model of organizational trust. Academy of management review, 20, 709-734.

Megawangi, R., Zeitlin, M. F., \& Colletta, M. D. (1995). The Javanese Family. In M. F. Zeitlin, R. Megawangi, E. M. Kramer, N. D. Colletta, E. D. Babatunde, \& D. Garman (Eds.), Strengthening the family: Implications for international development (pp. 95-141).Tokyo: United Nations University Press.

Möllering, G. (2001). The nature of trust: From Georg Simmel to a theory of expectation, interpretation and suspension. Sociology, 35, 403-420.

Murray, C. (2009). Parent and teacher relationships as predictors of school engagement and functioning among 
Tyas, T. H., Yuniarti, K. W., \& Kim, U.

low-income urban youth. Journal of Early Adolescence, 29, 376-404.

$<$ http://dx.doi.org/10.1177/0272431608322940>

Rousseau, D. M., Sitkin, S. B., Burt, R. S., \& Camerer, C. (1998). Not so different after all: A cross-discipline view of trust. Academy of Management Review, 23, 393-404.

$<$ http://dx.doi.org/10.5465/AMR.1998.926617>

Rozman, G. (1991). The East Asian region in comparative perspective. In G. Rozman (Ed.), The East Asian region: Confucian heritage and its modern adaptation. Princeton, NJ: Princeton University Press.

Yamagishi, T. (1998). Shinrai no kouzou: kokoro to syakai noshinka gemu [The Structure of Trust: The Evolutionary Games of Mind and Society]. Tokyo: Tokyo University Press.

Yamaguchi, S., \& Ariizumi, Y. (2006). Close interpersonal relationships among Japanese: Amae as distinguished from attachment and dependence. In U. Kim, K. S. Yang, \& K. K. Hwang (Eds.), Indigenous and cultural psychology: Understanding people in context (pp. 163-174). New York: Springer.

Yang, K. S. (2006). Indigenous personality research: The Chinese case. In U. Kim, K. S. Yang, \& K. K. Hwang (Eds.), Indigenous and cultural psychology: Understanding people in context (pp. 285-314). New York: Springer.

Williams, M. (2001). In whom we trust: Group membership as an affective context for trust development. The Academy of Management Review, 26, 377-396. 